\title{
DOS DELITOS E DAS PENAS NAS UTOPIAS DO SÉCULO XVI
}

\section{ON CRIMES AND PUNISHMENTS IN THE UTOPIAS OF SIXTEENTH CENTURY}

\author{
${ }^{1}$ Philippe Oliveira de Almeida
}

\section{RESUMO}

O objetivo deste trabalho é analisar os delitos e as penas na literatura utópica do século XVI. Inicialmente, é necessário desconstruir a idéia de que a utopia é um arcaísmo platonizante. Tal como os escritos políticos de Maquiavel, a literatura utópica representa uma tentativa de intervir em problemas jurídicos e sociais de seu tempo. É preciso, ainda, refutar o argumento de que a utopia é uma sociedade disciplinar, um antecessor dos regimes totalitários modernos. Autores como Morus e Rabelais tornaram-se aguerridos defensores das liberdades da sociedade civil contra ingerências arbitrárias do poder estatal. Mas também é necessário problematizar o mito de que a utopia seria um modelo de comunidade sem Estado. Morus, Campanella e Shakespeare reconhecem a importância das sanções penais para a preservação da ordem política.

Palavras-chave: Literatura utópica, Direito penal, Século XVI

\begin{abstract}
The goal of this study is to analyse the crimes and punishments in the utopian literature of the sixteenth century. Initialy, it is necessary to desconstruct the idea that utopia is a platonizing archaism. As the political writings of Machiavelli, the utopian literature is an attempt to intervene in legal and social issues of their time. It must also refute the argument that utopia is a disciplinary society, an ancestor of modern totalitarian regimes. Authors such as Morus and Rabelais have become seasoned defenders of the freedoms of civil society against arbitrary interference of State power. But it is also necessary to question the myth that utopia would be a model of stateless community. Morus, Campanella and Shakespeare recognize the importance of criminal sanctions for the preservation of political order.
\end{abstract}

Keywords: Utopian literature, Criminal law, Sixteenth century

\footnotetext{
${ }^{1}$ Doutorando em Direito pela Faculdade de Direito da Universidade Federal de Minas Gerais - FDUFMG, Minas Gerais (Brasil). Professor voluntário de Direito pela Universidade Federal de Minas Gerais - UFMG, Minas Gerais (Brasil). E-mail: philippeoalmeida@gmail.com
} 


\section{Introdução}

Este trabalho procura analisar os crimes e os castigos previstos na literatura utópica que germina no século XVI. ${ }^{1}$ Não tem a pretensão de exaurir a temática, mas tão-só identificar o sentido que, nas utopias do período, é conferido ao "Direito Penal" e ao "Direito Processual Penal" - ou, ainda, ao conjunto de normas e instituições responsáveis por prever e aplicar sanções penais. É considerável a distância, temporal e espacial, entre os textos utópicos da Primeira Modernidade. Todavia, a presença de tropoi recorrentes permite-nos identificar um diálogo intergeracional e transnacional, uma rede de influências, releituras e interferências que conecta autores os mais diversos no seio de uma mesma comunidade de conversação. ${ }^{2}$

Como ponto de partida de nosso estudo, focaremos as seguintes obras: De Optimo Reipublicae Statu deque Nova Insula Utopia (ou, simplesmente, Utopia), escrita por Thomas Morus (1478 - 1532) em 1516; La vie très horrifique du grand Gargantua, père de Pantagruel, volume, publicado em 1534, que compõe a série de romances escritos por François Rabelais (1494 - 1553) acerca de Gargântua e Pantagruel; La città del Sole, escrita por Tommaso Campanella (1458 - 1639) em 1602; e The Tempest, peça escrita por William Shakespeare (1564 - 1616) entre 1610 e $1611 .^{3}$ Elegemos as obras supracitadas em virtude do impacto que

\footnotetext{
${ }^{1}$ Este artigo foi desenvolvido como trabalho final da disciplina Temas de História do Direito - História do Direito Penal Moderno, ministrada pelo Professor Doutor Ricardo Sontag junto ao Programa de Pós-Graduação em Direito da Universidade Federal de Minas Gerais, no primeiro semestre de 2015.

${ }^{2}$ Uma introdução à utopia pode ser encontrada em ECO, 2013. Especificamente sobre o tema do artigo, impossível não fazer referência a JENDRYSIK, 2010. O texto de Jendrysik diferencia-se do nosso por não estabelecer marcos temporais precisos em sua análise das utopias na literatura. O ensaio inclui figuras tão distantes, no curso da história, quanto Thomas Morus, Russell Jacoby e Richard Dagger, procurando extrair conclusões abrangentes sobre o gênero utópico. Não é a abordagem que assumiremos, aqui, por acreditar-mos que uma maior precisão na delimitação do campo de análise pode permitir uma avaliação mais aprofundada. São exclusivamente as utopias renascentistas que tomaremos como foco. Relevante, ainda, para nosso trabalho, por apresentar estudo percuciente sobre a lei na literatura utópica, é o artigo RAMIRO AVILÉS, 2001.

${ }^{3}$ Procuramos, para as quatro obras referidas, estabelecer um cotejo entre uma edição estrangeira e uma edição pátria, da maneira como segue:

a) UTOPIA: MORE, Thomas. Utopia. London: Richard Chilmell, 1684 [o facsímile encontra-se disponível em $<$ https://archive.org/stream/utopia1684more\#page/n3/mode/2up>, acessado em 24 de junho de 2015]; e MORE, Thomas. Utopia. Tradução de Anah de Melo Franco. Brasília: Editora Universidade de Brasília; Instituto de Pesquisa de Relações Internacionais, 2004. (Col. Clássicos IPRI).

b) LA VIE TRĚS HORRIFIQUE DU GRAND GARGANTUA, PÈRE DE PANTAGRUEL: RABELAIS, François. Gargantua; Pantagruel. Paris: Larousse, 1932, 2 v.; e RABELAIS, François. Gargântua e Pantagruel. Tradução de David Jardim Júnior. Belo Horizonte: Itatiaia, 2009.

c) LA CITTÀ DEL SOLE: CAMPANELLA, Tommaso. La città del sole. Roma: Newton \& Compton, 1995 [o facsímile encontra-se disponível em <http://www.letteraturaitaliana.net/pdf/Volume_6/t332.pdf >, acessado em 24 de junho de 2015]; e CAMPANELLA, Tommaso. A cidade do sol. Tradução de Aristides Lobo. São Paulo: Atena, 1958.

d) THE TEMPEST: SHAKESPEARE, William. The Tempest. London: Macmillan and co., 1864 [o facsimile encontra-se disponível em 〈https://archive.org/stream/tempest03shakgoog\#page/n6/mode/2up>, acessado em 24 de junho de 2015]; e SHAKESPEARE, William. A tempestade. Comédias e romances: teatro completo, volume

2. Tradução de Bárbara Heliodora. Rio de Janeiro: Nova Aguilar, 2009.
} 
tiveram sobre o imaginário político do período, sendo representativas do gênero literário (a utopia) com o qual dialogam. ${ }^{4}$ Vale notar que, embora concebidas nos albores do século XVII, A cidade do sol e A tempestade ainda refletem os embates doutrinários que dominam o pensamento político do Cinquecento. Ademais, no tocante, especificamente, ao texto shakespeareano, cabe observar que A tempestade não representa, propriamente, uma utopia mas uma paródia que implode as regras do gênero, contendo utopias dentro de si. É a apreciação de uma dessas utopias que nos ocupará. ${ }^{5}$

Não trataremos de New Atlantis, obra de Francis Bacon (1561 - 1626) editada em 1627 - portanto, após sua morte (BACON, 1999). Isso porque, embora se constitua, juntamente com a obra de Morus, no mais emblemático exemplar da literatura utópica inglesa, jamais foi concluída por seu autor, que não teve a chance de abordar, no texto, questões relacionadas aos delitos e às penas. Por outro lado, teceremos breves comentários às epístolas apócrifas atribuídas a Américo Vespúcio (1454 - 1512) - Mundus Novus (de 1503) e Quatuor

Navigationes (escrita entre 1505 e 1506) (VESPÚCIO, 2003). ${ }^{6}$ Embora pretendam ser descrições do mundo novo descoberto pela Europa renascentista (e, notadamente, dos costumes de sua população), ditas cartas comportam projeções do que a mentalidade ocidental, à época, consciente ou inconscientemente concebia como uma organização político-jurídica ideal - razão pela qual foram fundamentais à eclosão da literatura utópica do século XVI, expressamente referidas por Morus e por outros que se aventuraram no gênero.

\section{A utopia é um arcaísmo platonizante?}

Antes de adentrarmos no tema proposto, faz-se mister formular algumas considerações sobre o sentido da literatura utópica, de forma geral.

Por questão estética, optamos por usar, nas citações das obras referidas, as traduções feitas para a língua portuguesa, com pequenas retificações onde estas parecem não atender plenamente ao sentido do texto original.

${ }^{4}$ Sobre o tema, recomendamos a leitura do dossiê Utopia como gênero literário, publicado, em 2005, no número 2 da revista Morus - Utopia e Renascimento, editada em Campinas.

${ }^{5}$ Os nomes e os sobrenomes dos autores que aqui trabalhamos tem (por questões que dizem respeito, entre outros fatores, à própria tensão entre cosmopolitismo humanista e incipiente nacionalismo, que marca o pensamento renascentista), com frequência, três versões: em latim; em sua respectiva língua vernacular; e em português. É o caso, por exemplo, de Thomas Morus (latim)/ Thomas More (língua vernacular)/ Tomás Moro (português). Optamos por utilizar, para cada um desses autores, o nome e o sobrenome por meio do qual ele é mais conhecido na literatura especializada publicada no Brasil - seja na língua latina, no vernáculo ou no idioma pátrio.

${ }^{6} \mathrm{O}$ volume contém cinco cartas, três autênticas (Carta de Sevilha, Carta de Cabo Verde e Carta de Lisboa) e duas apócrifas (Mundus Novus e Quatro Navegações). A tradução de Mundus Novus foi feita por Janaína Amado e Luiz Carlos Figueiredo; a de Quatro Navegações foi feita por João Angelo Oliva Neto. 
Não são raros os historiadores e os filósofos contemporâneos que encaram as utopias do século XVI como arcaísmos. O esforço para delinear a política, a religião, os costumes e a arquitetura de sociedades ideais trairia uma fantasia platonizante, tributária da recuperação renascentista da República (ARAÚJO, 2009). Em um mundo que assiste à difusão (frequentemente deturpada) da doutrina política de Nicolau Maquiavel $(1469-1527),{ }^{7}$ as discussões utópicas sobre a melhor forma de governo seriam resquícios de uma cosmovisão ultrapassada. Para os que adotam semelhante linha de argumentação, Il Principe (1513) demarcaria o crepúsculo dos "idealismos" antigo e medieval e o alvorecer do "realismo" moderno. ${ }^{8}$ Maquiavel seria o primeiro grande teórico da razão de Estado, que lançaria por terra a tradicional associação entre virtudes privadas e públicas, o campo do ético e o campo do político. Nessa esteira, qualquer obra, escrita após Maquiavel, que se investisse de uma natureza contra-fática, restaria - no entender desses pesquisadores - superada ab ovo.

Autor de obras sobre Campanella e sobre o sonho do paraíso terrestre, o historiador Jean Delumeau ${ }^{9}$ comunga de referidas leituras:

\begin{abstract}
As utopias do Renascimento, ligando-se, para lá da Idade Média, a uma corrente de pensamento muito antiga e a uma tradição platônica, mostravam-se indiscutivelmente inadaptadas ao presente. De certa maneira, os utopistas do século XVI e do início do século XVII estavam atrasados em relação ao seu tempo e não o compreendiam. Louvavam um estrito coletivismo na época em que se afirmava um individualismo que facilitava o erguer de nova civilização. Quando, no Ocidente, se desenvolvia o sentimento nacional, os utopistas construíam fora do tempo e do espaço estados sem tradição nem passado - estados que eram apenas cidades ou grupos de cidades. Ora, não provava a história daquele tempo que só as cidades podiam fazer a história? As literaturas européias iniciavam os seus vôos, mas Thomas More aplicou-se à criação de uma língua artificial. O capitalismo desenvolvia-se mas os utopistas recusavam a propriedade privada e a moeda. As grandes viagens marítimas multiplicavam as trocas entre continentes e estabeleciam ligações mais estreitas entre os povos, mas Thomas More, Stiblin, Campanella e Bacon conservavam no isolamento os estados dos seus sonhos. Finalmente, o Renascimento foi, em muitos aspectos, a descoberta da natureza; mas as utopias, em contrapartida, desconfiavam irremediavelmente de tudo o que é natural. (DELUMEAU, 1984, p. 30)
\end{abstract}

A perspectiva de Delumeu acerca das utopias é consentânea com a sua teoria de que a civilização do Renascimento - o processo que, a seu juízo, fez da Europa o centro dinâmico da

\footnotetext{
${ }^{7}$ Acerca do impacto de Maquiavel sobre o pensamento político moderno, v. POCOCK, 1975.

${ }^{8}$ No prefácio da tradução brasileira da Utopia que utilizamos neste trabalho (intitulado A utopia é um império: as relações entre os povos na obra clássica de Thomas More), o escritor e diplomata João Almino utiliza esses pólos ("realismo" e "idealismo") para opor Il principe à Utopia. O autor compreende o livro de Maquiavel como um libelo à unificação italiana, e interpreta o texto de Morus como um emblema da luta contra a organização social da monarquia inglesa.

${ }^{9}$ Sobre a vida e a obra de Delumeau, $v$. PIERONI, 2011.
} 
história - é uma emulsão composta por elementos antagônicos (cristianismo e paganismo, otimismo e pessimismo, credulidade e espírito crítico, razão e sem-razão, sombra e luz etc.), incapaz de sintetizar em um sistema único e homogêneo as forças que a atravessam. ${ }^{10}$ Bifronte, o Renascimento teria uma face voltada ao passado e outra voltada ao futuro - tendências “conservadoras" e "progressistas", disputando o coração do homem ocidental.

"Indiscutivelmente inadaptadas ao presente": a idéia de que uns estão "atrás" e outros "à frente" de seu próprio tempo sinaliza uma concepção teleológica da história. O nosso presente se afiguraria como meta, destino manifesto, do passado, e nós, os tardios, seríamos a medida de todas as coisas, o critério para avaliar as gerações pretéritas - dividindo os homens entre aqueles que catalizaram e aqueles que obstaculizaram a marcha inexorável do devir. Dessa maneira, um período - in casu, o século XVI - é julgado, não por seus próprios padrões, mas em função do que lhe antecede e do que lhe sucede. ${ }^{11}$

Não somos os interlocutores visados por Maquiavel ou Morus - e, nesse sentido, quando encontramos (ou julgamos encontrar) nesses autores a antecipação de nós mesmos, não fazemos mais que apropriações indébitas. Como diria Nietzsche: "Quando não se tem um bom pai, é preciso inventar um". ${ }^{12}$ Junto às rodas de conversa dos humanistas do Renascimento, não somos mais que visitantes inesperados, "penetras". Tanto Maquiavel quanto Morus escrevem aos homens de seu próprio tempo, guiados pelo interesse de intervir em conjunturas que a eles se impunham naquele momento. Ignorar o fato, apreciando-os exclusivamente à luz do porvir, é traí-los.

Qual, então - para além de uma suposta vocação antiquária -, a causa que mobiliza os utopistas? Como a literatura utópica se inscreve no pensamento político de seu tempo?

\footnotetext{
${ }^{10} \mathrm{~A}$ propósito, afirma o historiador: "Todas as épocas tem os seus contrastes, mas esta tem mais que as outras. Não apresenta a unidade de cores nem a homogeneidade, pelo menos relativa, do século XVII. Por isso, não tentemos distinguir, com H. Haydn e E. Battisti, numa Europa em vias de renovação como a dos séculos XV e XVI, um 'Renascimento' e um 'Anti-Renascimento' que caminhassem a par, tendo o segundo sido, segundo um, mais experimental e, segundo o outro, mais barroco que o primeiro. Digamos, em vez disso, que o Renascimento foi, ao mesmo tempo, razão e sem-razão, sombra e luz. [...] Comparável ao adolescente em que lutam fogosamente forças opostas e que ainda não alcançou o equilíbrio, foi mais ambicioso que razoável, mais brilhante que profundo, mais tenso que eficaz. O Renascimento foi variedade, jogo de contrários, exploração ardente e, por vezes, esboçada de um universo de novidades". (DELUMEAU, 1984, p.125)

${ }^{11}$ Facilmente nos esquecemos de que o futuro do pretérito não é o presente - quer dizer, o futuro esperado e temido pelos homens de outrora, por eles imaginado, não corresponde ao tempo que se realiza na contemporaneidade. $\mathrm{O}$ presente é, ao contrário, a frustração das expectativas do passado. Dessa maneira, por mais que o queiramos (movidos pela crença, compartilhada ao menos desde a primavera da Cristandade, de que o agora em que vivemos é um momento privilegiado da história, às vésperas da revelação), não somos nós os destinatários finais das obras produzidas por nossos antepassados.

${ }^{12}$ Acerca das reflexões nietzscheanas sobre a história, recomendamos a leitura de ALMEIDA, 2012. Nietzsche, que apresentou severas críticas às visões teleológicas, possui importantes reflexões sobre a história e a historiografia. A propósito, v. NIETZSCHE, 2005.
} 
Pretendemos, incidentalmente, esboçar uma resposta à questão, na medida em que respondermos ao problema central que nos colocamos neste artigo, isto é, a presença dos delitos e das penas nas utopias.

\section{A utopia é uma sociedade disciplinar?}

As cidades planejadas tornaram-se, no mundo contemporâneo, símbolos das potencialidades e dos limites da razão. Expressões do progresso tecnocientífico, são arquitetadas com o intuito de antecipar variáveis naturais e humanas. O planejamento urbano feito in abstracto ignora os valores regionais em prol de modelos gerais baseados na funcionalidade. Para uns, trata-se de libertação - do indivíduo face aos condicionamentos impostos pelas tradições locais. Para outros, constitui-se em opressão - de grupos vulneráveis, com suas crenças e hábitos específicos, frente à massificação. A arquitetura e o urbanismo tornaram-se, assim, zonas de conflito, na guerra entre os herdeiros do iluminismo e do romantismo, que disputam, há séculos, pelo direito de definir qual o verdadeiro valor da racionalidade moderna. O combate entre a Bauhaus (escola de design, artes plásticas e arquitetura fundada pelo funcionalista Walter Gropius em 1919) e as tendências pós- modernistas retrata exemplarmente a tensão em torno da cidade planejada. ${ }^{13}$

Muitos associam o planejamento urbano à sociedade disciplinar - ao controle social por meio da vigilância. Após as reformas de Paris por Haussman, todos os centros urbanos se transformariam, progressivamente, em grandes instalações panópticas. Desse ponto de vista, a tentativa, nas cidades planejadas surgidas a partir do século XIX, de subordinar a desordem à razão instrumental encontrariam precedentes nas utopias do século XVI. A utopia seria o ancestral direto da cidade planejada - e, por conseguinte, do panóptico:

\footnotetext{
${ }^{13}$ Duas obras representativas do embate ideológico entre a Bauhaus e o pós-modernismo são: $1^{\text {a }}$ ) acerca do pósmodernismo, VENTURI, Robert et al. Aprendendo com Las Vegas: o simbolismo (esquecido) da forma arquitetônica. Tradução de Pedro Maia Soares. São Paulo: Cosac \& Naify, 2003; e 2a) acerca da Bauhaus, GROPIUS, Walter. Bauhaus: novarquitetura. Tradução de J. Guinsburg e Ingrid Dormien. São Paulo: Perspectiva, 2004. Em uma passagem do segundo livro indicado, de texto datado de 29 de maio de 1934, Gropius parece antecipar-se às críticas ao funcionalismo que, a partir dos anos 70, se tornarão correntes [p. 108]: "Sou da opinião de que nossa concepção das tarefas da nova arquitetura nunca ataca o conceito da tradição, pois o respeito à tradição não significa o prazer do agradável ou cômoda ocupação, estético-formalista, com formas artísticas passadas, mas foi e sempre é luta pelo essencial, portanto por aquilo que está por trás da matéria e da técnica e que com sua ajuda procura sempre a expressão visível".
} 


\begin{abstract}
As soluções que a Razão encontra para as cidades no século XIX são bastante distintas. Alguns evocam o pensamento renascentista de Thomas Morus e retomam a Utopia: Charles Fourier imagina os falanstérios; James Buckingham elabora Victoria, Etienne Cabet descreve Icária; Godin desenha o familistério de Guise, Benjamin Richardson projeta Hygea e até mesmo Julio Verne sonha com Franceville. Em qualquer um desses projetos utópicos não há lugar para a desordem. A ordem é o principal produto da Razão, que confere às cidades higiene, beleza, retidão, amplidão, claridade e, na maioria das utopias, igualdade e felicidade. (GARCIA, 2008, p. 20)
\end{abstract}

As críticas às experiências totalitárias e ao higienismo social, nos séculos XX e XXI, ampararam-se, com frequência, na literatura distópica (GOTTLIEB, 2001). Nas distopias, as tentativas de subordinar o real ao ideal, o fático ao contra-fático - de modelar o cotidiano da comunidade política a partir de uma representação mistificada da ordem social -, culminaria em práticas despóticas. As distopias mostram-se, assim, como o reverso da medalha, o outro lado da meia-noite, a desconstrução do programa moderno de Aufklärung. Pretendem desmascarar os impulsos absolutistas do humanismo. É provável que a primeira obra emblemática, no século passado, a partir do esquema supra-referido, tenha sido A modern utopia, escrita por H. G. Wells e editada em 1905.

Avaliar a literatura utópica do século XVI a partir das frustações contemporâneas diante dos fracassos da racionalidade instrumental é empresa assumidamente anacrônica, posto que julga tais textos a partir dos usos (evidentemente diversos dos que foram pensados por seus autores) que receberam três séculos depois de escritos. Contudo, se tornará tática comum utopias interpretadas como distopias que não sabem de si -, contaminando os (parcos) esforços no sentido de apreciar as normas e as instituições penais presentes em autores como Morus e Campanella. As utopias seriam, em última instância, versões rudimentares, esboços, da sociedade disciplinar - o que faria dos utopistas incorrigíveis inimigos da sociedade aberta. ${ }^{14}$

Abordagem semelhante pode ser encontrada em "Il deviante nella città perfecta. Modelli repressivi nelle utopie di Campanella e More”, artigo de Maria Laura Tasso. (TASSO, 1999) Tasso toma Michel Foucault ${ }^{15}$ como marco de referência para analisar Utopia e A cidade do sol. Para Tasso, em última instância, toda a cidade perfeita pode ser vista como um maquinário de repressão sobre potenciais desviantes. Assim, a autora não procura compreender como os delitos e as penas se inscrevem no interior das utopias; mas como as utopias se situam no seio

\footnotetext{
${ }^{14}$ Com efeito, no infame A sociedade aberta e seus inimigos, Karl Popper intitula "mecânica utópica" as tentativas de, por meio da violência, impôr reconstruções sociais a partir de ideais absolutos e imutáveis. V. POPPER, 1974, p. 172 a 183.

${ }^{15}$ A autora se vale, antes de mais, da obra Vigiar e punir, que encontra-se editada em nossas plagas: FOUCAULT, 1987. O impacto do pensamento filosófico de Foucault sobre a historiografia contemporânea pode ser mensurado pelos encômios que o importante acadêmico Paul Veyne tece ao intelectual francês em VEYNE, 1982.
} 
da sociedade disciplinar. Tasso não reconhece distinções no tratamento que o ordenamento jurídico utópico dá às infrações e a outras formas de relação social. O Direito na literatura utópica, em sua integralidade, teria, para a autora, natureza penal, um prenúncio dos regimes totalitários do século XX.

Leitura oposta - mas igualmente reducionista - pode ser encontrada em "Crime and Punishment in Classical and Libertarian Utopias", de Vicenzo Ruggiero. (RUGGIERO, 2013) Para Ruggiero, Morus e Campanella teriam, em um mundo que assiste à emergência do poder disciplinar, se insurgido, apresentando, em suas obras, projetos com cariz anarquista e abolicionista. Provavelmente mais simpático ao planejamento urbano no mundo contemporâneo, Ruggiero destaca a dimensão emancipatória da racionalização da vida comuntária. Uma vez mais, deixa-se de avaliar o que os utopistas de fato disseram sobre crime e castigo, em nome de especulações acerca de possíveis elos genealógicos entre conceitos do Direito Penal moderno e a literatura utópica.

Contra os vícios dos estudos suprareferidos, procuraremos, adiante, enfrentar as passagens, nos livros que selecionamos, que tratam diretamente de delitos e penas, tentando, na medida do possível, livrarmo-nos dos filtros que as distopias contemporâneas poderiam representar.

\section{Das penas no mundo novo}

Não é possível falar das utopias do século XVI sem citar as cartas Mundus Novus e Quatro Navegações, atribuídas, no período, a Américo Vespúcio. Embora tenhamos, hoje, acesso a cartas autênticas do pensador florentino acerca do novo mundo, foram os dois textos apócrifos - de caráter deveras sensacionalista, nas descrições da natureza e das gentes das terras recém-descobertas - que exerceram impacto sobre a mentalidade européia. É em virtude das duas cartas que o novo continente recebeu o nome que tem. Há estreita conexão (na forma e no conteúdo) entre as utopias e as epístolas atribuídas a Vespúcio. A literatura utópica reiteradamente fará remissão às cartas e a Vespúcio. Ademais, parcela substantiva das obras dos utopistas - a Utopia de Morus e a Nova Atlântida de Bacon podem ser citadas como exemplos - se estruturarão como narrativas de navegações.

É provável que Mundus Novus e Quatro Navegações, que tiveram, já nos primeiros anos do século XVI, inúmeras edições, em latim e em línguas vernaculares, tenham se apresentado 
ao Ocidente como impactantes exercícios de "relativismo cultural". Se Jerusalém não é o centro do mundo - noutras palavras, se existem povos que, ao menos aparentemente, não tomam parte na história da salvação tal como ela se desenvolvera até aqui -, então é preciso rever o que se considera, nas organizações humanas, o limite entre o natural e o adquirido, entre comportamentos que estariam inscritos na própria natureza humana e hábitos socialmente construídos. Talvez seja essa a principal função política da literatura utópica que, após a publicação das duas cartas, despontará: relativizar (historicizar ou, ainda, desnaturalizar) instituições até então consideradas como inatas (o casamento, por exemplo). Dessa forma, poderíamos encarar as utopias como um - para fazer remissão à terminologia de Roberto Mangabeira Unger - ensaio de imaginação institucional, de desconstrução do fetichismo institucional. ${ }^{16}$

Tanto Mundus Novus quanto Quatro Navegações ocupam-se da relação dos canibais com a lei. A propósito, em Mundus Novus, o Pseudo-Vespúcio afirma:

Quantas vezes querem, desfazem os casamentos, nos quais não observam nenhuma ordem. Além do mais, não têm nenhum templo, nenhuma lei, nem são idólatras. Que mais direi? Vivem segundo a natureza e podem ser considerados antes epicuristas do que estóicos. Entre eles não há mercadores nem comércio das coisas. (VESPÚCIO, 2003, p. 42) ${ }^{17}$

À diferença da carta de Colombo, as cartas do Pseudo-Vespúcio procuram acentuar as dessemelhanças (e não as semelhanças) entre os povos recém-descobertos e as lendas sobre os antípodas e os reinos imaginários que pululavam nas mentes dos europeus de então. Na Quatro Navegações, cuidando, especificamente, dos delitos cometidos pelos indígenas, o autor dirá: "Não observam nenhum direito e nenhuma justiça, não punem os malfeitores, mas, ao contrário, os próprios pais não educam nem repreendem os pequenos. E com surpresa raramente os vimos altercar-se entre si” (VESPÚCIO, 2003, p. 73). Não passará desapercebida a Michel de Montaigne (1533 - 1592), uma das inspirações de Shakespeare na composição d'A tempestade, a observação de que, à paz social no seio da tribo de autóctones, seria dispensável a presença

\footnotetext{
${ }^{16}$ Sobre os conceitos de imaginação institucional e fetichismo institucional em Unger, recomendamos a leitura de UNGER, 1996.

${ }^{17}$ Em Quatro Navegações consta passagem semelhante: "Vimos que naquela gente ninguém observa lei alguma, não podendo com motivo sólido ser considerados judeus ou mouros, já que são muito piores que os próprios gentios ou pagãos, pois não notamos que fizessem sacrifícios ou que possuíssem locais ou casas de oração. A vida que levam, de todo voluptuosa, considero epicurista". VESPÚCIO, 2003, p. 75.
} 
de um aparato coercitivo. ${ }^{18}$ Também Rabelais parece explorar tal crença, ao erigir sua Thélème, como mais à frente veremos.

\section{Das penas na Utopia}

Embora a utopia de Morus tenha ordem, templo, lei e ídolos - e seus residentes possam ser considerados antes estóicos que epicuristas -, é notório o esforço para dissociar paz social e cominação de penas, o que pode representar influência do Pseudo-Vespúcio. O diálogo dividese em duas partes: a segunda, escrita quando o autor ainda encontrava-se em Flandres, tem nítida inspiração nas descobertas marítimas portuguesas; a primeira, redigida quando do regresso de Morus à Inglaterra, demarca a função de crítica social da obra. Longe de serem naturais, as formas de governo são produtos da história e da experiência - logo, o contato com povos estrangeiros pode fornecer mecanismos para o aperfeiçoamento das instituições públicas Em dito diálogo, o autor fala de como instituições de "povos recentemente conhecidos" poderiam servir como "bons exemplos" para que possamos "corrigir os abusos que se cometem nas nossas cidades, em nossas nações e em nossos povos e reinos” (MORE, 2004, p. 8 e 9). Um dos principais "abusos" que Morus denuncia é a falta de equidade na estipulação dos delitos e das penas, bem como a exploração econômica que leva os pobres ao banditismo: "Os ladrões são condenados a um suplício cruel e atroz, quando seria preferível assegurar a subsistência de cada um, de maneira a que ninguém se encontrasse diante da necessidade de roubar para ser, em seguida, executado" (MORE, 2004, p. 13). O trecho citado é, parece-nos, prova mais do que suficiente de que Tasso erra ao ver em Morus um ancestral da sociedade disciplinar e dos regimes nazi-fascistas. Morus fala dos camponeses que, enganados ou expulsos à força, cedem suas terras, para que sejam transformadas em pastagens para carneiros. Levados, pela miséria, ao crime, são violentamente punidos pelo poder público, que não atenta para a crise social que fomenta o delito:

\footnotetext{
Se não for possível encontrar remédios para esses males, torna-se fútil gabar-se dessa justiça que sabe tão bem reprimir o roubo, e qualquer política se afigurará superficial, tal como a justiça, que não é nem justa, nem eficaz. Se permitis que vossos jovens cresçam num meio onde seus costumes são, passo a passo, abominavelmente corrompidos desde os mais tenros anos e se, na idade adulta, os pune por crimes para
}

\footnotetext{
${ }^{18} \mathrm{O}$ célebre ensaio de Montaigne pode ser encarado como um exercício de alteridade, no qual o autor se esforça para desconstruir a condenação moral dos europeus aos costumes dos povos ameríndios. $V$. MONTAIGNE, 2010.
} 
os quais foram literalmente preparados, que fazeis deles senão ladrões, para que mais tarde sejam castigados? (MORE, 2004, p. 20)

Morus, que tinha formação jurídica e exerceu diversos cargos públicos (incluindo o de Lord Chancellor) durante o reinado de Henrique VIII, é considerado (juntamente com William Lilly, Colet e Erasmo de Roterdã) um dos apóstolos do new learning, projeto de reforma pedagógica e social influenciado pelo Renascimento Italiano. A condenação à exploração dos pobres pelos ricos era tema central para partícipes do new learning. A dinastia Tudor, iniciada com o fim da Guerra das Rosas (e a união das casas dos York e dos Lancaster) representou a decadência do feudalismo - haja vista que impulsionou a centralização do poder político. Contra a nobreza armada (constituída grosso modo por senhores feudais, detentores de vastas porções de terra) os Tudor estimularão a ascensão social da burquesia e da nobreza togada - que orbitarão em torno da Corte. O fenômeno incitará a capitalização do campo, com a consequente expulsão dos servos, obrigados a migrar para grandes centros urbanos e trabalhar em condições degradantes. O processo - visto, hoje, como fundamental à modernização da Inglaterra - trouxe, à época, pauperização das condições de vida de muitos, levados à mendicância e à criminalidade. Para Morus, é o governo o responsável pela violência que ele procura combater por meio do recrudescimento das normas penais e da convergência do poder punitivo nas mãos do rei. Morus, que atuou na política desde o governo de Henrique VII, sempre apresentou-se como crítico das implicações sociais acarretadas pelas mudanças políticas descritas - não rejeitando, no entanto, a centralização do poder em si mesma, e participando, ele próprio, da nobreza togada. ${ }^{19}$

A descrição da ilha de Utopia surge, no texto de Morus, como contraponto às arbitrariedades do poder judiciário inglês. Diversamente do que propõe Ruggiero, Morus está longe de ser abolicionista ou anarquista. Os ex-cidadãos de Utopia que cometeram crime abjeto, bem como os miseráveis de outras nações e as pessoas condenadas à morte em seus respectivos países, são submetidas à escravidão em Utopia - prática que, no entender de Morus, teria função pedagógica (MORE, 2004, p. 91 e 92).

No que tange aos procedimentos a serem adotados para o julgamento de infratores, Morus entende que, salvo em caso de faltas graves, que afetem o interesse público, devem ser

\footnotetext{
${ }^{19}$ Sobre a conjuntura política européia durante a vida de Morus, v. FLOWER, 1896. O livro de Benjamin Orange Flower (1858 - 1918) é delicioso exemplo das desleituras modernas da Utopia. Jornalista emblemático da progressive era norte-americana (período que vai da década de 1890 à década de 1920, marcada por um ativismo político voltado à "modernização" do aparelho estatal e ao empoderamento da sociedade civil), B. O. Flower encontra em Morus uma matriz da doutrina progressista disseminada em sua própria era.
} 
os maridos os responsáveis pela punição das esposas, e os pais os responsáveis pela punição dos filhos. Morus condena a diferenciação entre crime tentado e crime consumado, e rejeita o excesso de produção normativa - em seu entender, é o juízo de equidade, o senso de justiça, e não as estreitas malhas da lei, que deve nortear a "tipificação dos crimes" e a aplicação das penalidades:

\begin{abstract}
Os utopienses consideram totalmente injusto obrigar os homens a cumprir tantas leis que são, na verdade, demasiadamente numerosas para serem lidas e obscuras demais para serem compreendidas. Por isso, em Utopia, não há trabalho para o advogado, cujo ofício se resume na manipulação de processos e na multiplicação de interpretações astuciosas. (MORE, 2004, p. 91 e 92)
\end{abstract}

\title{
6. Das penas na Abadia de Thélème
}

Após viajar por toda a França, Rabelais decidiu estudar medicina. Era nos textos sobre a área, e não em seus trabalhos literários, que o autor acreditava estar seu legado. Rabelais não encarava A vida de Gargântua e Pantagruel como representativa do humanismo francês - não levantava grandes pretensões acadêmicas, buscando em sua obra, tão-só, satisfazer interesses econômicos. ${ }^{20} \mathrm{O}$ livro sinaliza o fim da literatura de cavalaria - e, em última instância, a crise do ideário medieval. Com efeito, como sugere René Millet, a obra de Rabelais pode ser interpretada como uma sátira contínua e difusa da Idade Média (MILLET, 1892, p. 123). Rabelais vê o ascetismo e a escolástica - que dominam a cultura tardo-medieval - como grilhões da carne e do espírito. Trata-se da "revanche da besta oprimida" (MILLET, 1892, p. 82).

Rabelais é - segundo Millet - "um humanista que fala a língua do povo", "aliança imprevista de faculdades diversas", que une erudição e imaginação. Sua "poesia da vida real" opõe-se ao mundo abstrato dos literatos. Herdeiro dos fablieux medievais ("contos em versos para rir", pulp-fiction comum ao fim do Medievo), ${ }^{21}$ Rabelais elege os monges e os juristas como principais objetos de suas críticas aos costumes. É notória, de fato, a repugnância expressada por Rabelais - que manteve amizade com diversos magistrados, ao longo de sua

\footnotetext{
${ }^{20}$ Como diria Samuel Johnson (1709 - 1784), maior dentre os críticos literários de língua inglesa: "ninguém, a não ser um idiota, escreve a não ser por dinheiro".

${ }^{21}$ Uma diversificada compilação, comentada, de fablieux pode ser encontrada em SCOTT, 1995.
} 
vida - pelas "gentes da lei" (MILLET, 1892, p. 145). Os juristas foram os principais responsáveis, no século XVI, por forjar o aparato conceitual que fundamentou o poder absoluto do rei. Atuaram, nesse sentido, como (na expressão de Millet) "sutis advogados do absolutismo". À época de Rabelais, o aparelho judicial, na França, começava a, progressivamente, confundir-se com o aparelho administrativo - o rei, dia a dia, tornava-se o juiz supremo, concentrando em suas mãos o poder judicante e legiferante. ${ }^{22}$ Natural que Rabelais, aguerrido defensor das liberdades da sociedade civil, veja o jurista do Cinquecento com desconfiança.

À diferença da ilha de Utopia, a Abadia de Thélème, na obra de Rabelais, não é encontrada, mas construída - para recompensar um monge, o gigante Gargântua cria uma abadia ao seu gosto, "ao contrário de todas as outras". Não temos, assim, uma narrativa de navegação que anteceda a apresentação da utopia. O leitor é convidado a acompanhar, tijolo a tijolo, a fundação de Thélème. “A maior ilusão deste mundo é se governar ao som de um sino, e não pelo bom senso e pelo entendimento" (RABELAIS, 2009, p. 218). A frase do monge indica que não serão regras formais, mas a sapiência, que norteará a ordem jurídica da abadia. Sobre a grande porta da construção, há um poema que, entre outros, critica os homens associados ao poder judiciário:

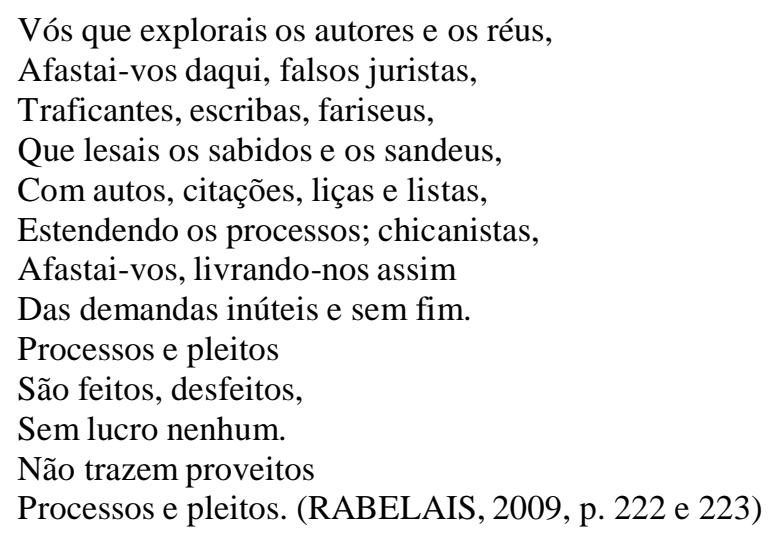

Thélème é um estuário de concórdia em um período marcado pelo conflito. Se para nós, o século XVI avulta, em retrospecto, como a era do Renascimento e da Reforma, para seus contemporâneos a época é de guerra (MILLET, 1892, p. 107). Ao fim da vida, Rabelais se

\footnotetext{
${ }^{22}$ Um sintoma desse processo é a gradual conversão do direito costumeiro (fundamentado na tradição) em lei escrita (legitimada pelo poder régio). Costumes serão pesquisados, compilados e publicados pelo monarca, que suprimirá as especificades destes face aos atos típicos de seu poder legislativo (ordonnances, lois, edits). A propósito, v. MORTARI, 1972.
} 
mostrará profundamente decepcionado com as guerras religiosas - o esforço para impôr a fé por meio da força. "Faze o que quiseres" - é essa a única regra de Thélème. Para Rabelais, a ausência de "vil sujeição e constrangimento", a inexistência de aparato coercitivo, é, precisamente, o que desestimula a prática de crimes: "Porque as pessoas liberadas, bem- nascidas, bem instruídas, convivendo com gente honesta, têm por natureza um instinto e estímulo que sempre as impele para a virtude e as afasta do vício; a que chamam honra" (RABELAIS, 2009, p. 230). Em um mundo no qual não existam penas, o "jugo da servidão", tampouco existirão delitos, pois é a proibição que incita à transgressão. Tal como em Morus, a criminalidade na Europa é explicada, por Rabelais, em termos de crise social - a solução se apresentando, não em castigos rigorosos, mas em maior participação do povo nas benesses materiais e espirituais adquiridas pela comunidade.

\section{Das penas na Cidade do Sol}

No que diz respeito à estipulação de delitos e penas, a obra mais fecunda, dentre as aqui apresentadas, é, indubitavelmente, A cidade do sol. Campanella foi educado pelo tio paterno, professor de Direito em Nápoles, e sua obra, com frequência, aborda problemas jurídicos - antes de tudo, a relação entre poder secular e poder eclesiástico (BALDACCHINI, 1847). Embora estudasse Direito, Campanella manifestou, desde tenra idade, o desejo de tornar-se monge dominicano, movido pela admiração que sentia pelo pensamento de Alberto Magno e Tomás de Aquino. Desde a juventude, o pensador rejeitou a filosofia aristotélica - o que, considerando sua admiração pelo Aquinate, não deixa de ser paradoxal. Cedo abraçou a doutrina de Bernardino Telesio (1509 - 1588), professor de filosofia natural em Nápoles, que tinha por objetivo apresentar uma alternativa moderna ao pensamento do Estagirita (adotado por muitos, então, como única via possível de acesso à verdade).

Campanella também interessou-se pelo estudo da medicina e da "ciência oculta" (uma simbiose de cabala, alquimia, astrologia e magia, popular na Renascença). Sua perspectiva heterodoxa - anti-escolástica - despertará suspeitas de heresia e rebelião. Acusado de conspirar para que o império turco, contra a ocupação espanhola, invadisse a Calábria e libertasse a região, Campanella foi preso e torturado (permanecendo no cárcere de 1599 a 1626). Foi na prisão que Campanella compôs A cidade sol. 
Descoberta, tal como a ilha de Utopia, após um incidente em uma viagem marítima, a comunidade política idealizada por Campanella é regida por magistrados, responsáveis, cada um, pela manutenção de uma virtude específica (Magnanimidade, Fortaleza, Castidade etc.). Entre os magistrados, Campanella prevê relações hierárquicas - que refletem a ordem que as virtudes devem ocupar na formação do caráter.

A violação de qualquer um desses valores morais pode e deve ser punida pelos magistrados. A retidão ética dos cidadãos é de responsabilidade do poder público, portanto. Segundo Campanella, "as penas mais em voga são a privação da mesa comum e a proibição das mulheres e de outras honras, pelo tempo que o Juiz julgar necessário para a correção" (CAMPANELLA, 1958, p. 16). Há na Cidade do Sol, no entanto, excessos mais graves, puníveis com penas mais rigorosas: “o exílio, a pancada, a desonra, a privação da mesa comum, a interdição ao templo, a proibição das mulheres", bem como a pena de morte (CAMPANELLA, 1958, p. 44). Tais penas, porém, caso o delito não tenha sido doloso, deverão ser, no entendimento de Campanella, dosadas pela misericórdia do magistrado.

Não há prisões na Cidade do Sol - salvo uma torre destinada a inimigos do Estado e rebeldes, e que Campanella não vê como medida jurídica, mas política. Todo acusado tem direito a um devido processo judicial, e a alguns condenados à morte é faculdado escolher como a sentença deverá ser executada.

Embora seja, dentre os utopistas tratados neste trabalho, o que maior atenção dá à punição do infrator, Campanella também acredita - tal como Morus e Rabelais - que a redução da criminalidade se encontra associada à educação cívica da população e ao reparto de bens. Se a sociedade é um corpo, a cabeça - os governantes - devem ser temperantes, e distribuir as riquezas para todos os membros de maneira equânime, para que não haja conflito.

\section{Das penas na ilha de Caliban: a crítica de Shakespeare aos utopistas}

Shakespeare, como acima antecipamos, não concebe uma utopia - no entanto, $A$ tempestade dialoga continuamente com a literatura utópica. Próspero, o Duque de Milão, é deposto injustamente por seu irmão, que o lança, com sua filha, ao mar. A narrativa de navegação, característica das utopias, retorna, pois, na peça. Aportando em uma ilha 
desconhecida, o governante deposto - que, como o Fausto de Christopher Marlowe, ${ }^{23}$ detém conhecimento de magia - cria, ex nihilo, uma nova cidade, composta unicamente por ele próprio, por sua filha, pelos espíritos que evoca (dentre os quais se destaca Ariel), e Caliban, o verdadeiro dono da terra conquistada - cujo nome, sugestivo, é um anagrama de "canibal" (como dissemos acima, Shakespeare conhece o trabalho de Montaigne, e há, n'A tempestade, passagens que a literatura especializada associa ao ensaio Dos canibais, acima citado).

Valendo-se das artes ocultas, Próspero, vários anos após seu exílio, consegue conjurar uma tempestade que arrasta, para a ilha, uma comitiva de homens associados à sua deposição. Perdido no ambiente inóspito, um dos homens - Gonzalo, um conselheiro velho e honesto, que tentara ajudar Próspero, quando da usurpação - especula como seria a ilha, caso fosse ele seu governante. Em poucos versos, Shakespeare concebe, com a fala de Gonzalo, uma sociedade ideal, que tem muitos pontos de contato com os mundos imaginados pela literatura utópica precedente - vale lembrar que Shakespeare é um dos possíveis autores da peça Sir Thomas More, obra colaborativa proposta por Anthony Munday e Henry Chettle da qual muitos escritores elizabetanos teriam participado. Segue a passagem, in verbis:

GONZALO - Se a ilha fosse minha plantação, senhor...

ANTÔNIO - Semeava de espinhos.

SEBASTIAN - Ou de malva.

GONZALO - E sendo dela o rei, o que faria?

SEBASTIAN - Ficava sóbrio, por falta de vinho.

GONZALO - Pro bem-estar geral, eu contra os hábitos

Faria tudo. Pois nenhum comércio

Admitiria. E nem magistrados; Nada

de letras. Riqueza e pobreza, Qual

serviços, nada. Nem sucessões,

Contratos, vinhas, limites de terra;

Nem uso de metais, milho, óleo ou vinho.

Nenhuma ocupação. No ócio o homem,

Como a mulher, mas puros e inocentes,

Nada de soberania.

SEBASTIAN - E ele rei.

ANTÔNIO - O fim do bem-estar geral esqueceu do começo.

GONZALO - A natureza fartaria a todos

Sem esforço ou suor. Traição e crime,

Espadas, facas ou necessidade

De todo engenho eu jamais teria.

Pois de si jorraria a natureza

Em abundância sua colheita boa,

Pr'alimentar o meu povo inocente.

SEBASTIAN - Nada de casamentos entre os súditos?

ANTÔNIO - Nada, homem; todos no ócio - putas e calhordas.

GONZALO - Governaria eu tão bem, senhor,

Que excederia a Idade do Ouro. (SHAKESPEARE, 2009, p. 1535 e 1536)

\footnotetext{
${ }^{23}$ Não somos os primeiros a comparar os personagens de Marlowe e Shakespeare. A propósito, recomendamos a leitura da introdução feita por Dirceu Villa à peça de Marlowe, publicada em MARLOWE, 2006.
} 
As ironias de Antônio e Sebastian não devem ser vistas como a visão de Shakespeare no que toca às utopias - afinal, são ambos usurpadores, não tendo portanto a mais abalizada das opiniões quanto à melhor forma de governo. Necessário entender, no entanto, que Gonzalo era o conselheiro de um soberano (Próspero) deposto precisamente porque, dedicando-se aos livros, não se ocupou dos assuntos de Estado (que, na prática, já tinham se tornado, antes da usurpação, responsabilidade do irmão). Shakespeare, cuja família prosperou durante a dinastia Tudor, em diversos momentos de sua obra manifesta simpatia por governos centralizados - associando a partilha da autoridade aos riscos da guerra civil. Assim, acredita que uma sociedade sem "soberania" não conseguiria encontrar a paz. ${ }^{24}$

Como o erudito Stephen Greenblatt destaca, o Bardo Inglês tinha sensibilidade para reconhecer a necessidade da utilização da força por parte do Estado, em um tempo - como era o elizabetano - dominado por conflitos internos e pela iminência da guerra civil (GREENBLATT, 2011). Elizabeth - e seu sucessor, Jaime I - acentuarão o processo (em curso desde Henrique VII, como já vimos ao comentar a obra de Morus) de centralização do poder político e jurídico. Os ideais conservadores assumidos por Shakespeare o levarão a apoiar o programa da coroa. Assim, não é de estranhar que veja com sarcasmo o sonho, aventado por Gonzalo, de uma sociedade livre de penas. Se, como entende Max Weber, o Estado moderno se constitui no monopólio do uso legítimo da violência, ${ }^{25}$ então é com a era elizabetana que o projeto de modernização da vida pública se consolida na Inglaterra. O trono fartamente recorrerá à perseguição, à prisão e à morte dos opositores políticos, assumindo-se como única

\footnotetext{
${ }^{24}$ Sobre o tema, Bárbara Heliodora discorre, em obra clássica acerca do pensamento político shakespeariano: "Dado que, historicamente, o advento da dinastia Tudor e o casamento de seu fundador, Henrique Richmond (herdeiro dos Lancasters), com Elizabeth de York correspondem ao término da Guerra das Rosas, é compreensivo que a paz subseqüente tenha sido particularmente bem vinda para aqueles que trabalhavam a terra e durante anos haviam parado de fazê-lo para lutar naquele inglório conflito interno, responsável pela destruição de incontáveis vidas e fortunas. [...] Por outro lado, a gritante precariedade do direito de Henrique Richmond à coroa inglesa fez com que nos primeiros doze anos de seu reinado (que durou de 1485 a 1509) houvesse uma série de tentativas dos partidários da casa de York para tirá-lo do trono. Tais ameaças naturalmente justificaram uma série de contramedidas, via de regra entusiasticamente apoiadas por aqueles que, como os Shakespeares, prosperavam com a paz, e tal apoio implicava na aceitação de um novo tipo de governo, centralizado [...]”. HELIODORA, 1978, p. 39.

${ }^{25}$ Nas palavras de Weber: "De modo geral, o desenvolvimento do Estado moderno tem por ponto de partida o desejo de o príncipe expropriar os poderes 'privados'independentes que, a par do seu, detêm força administrativa, isto é, todos os proprietários de meios de gestão, de recursos financeiros, de instrumentos militares e de quaisquer espécies de bens suscetíveis de utilização para fins de caráter político. Esse processo se desenvolve em paralelo perfeito com o desenvolvimento da empresa capitalista que domina, a pouco e pouco, os produtores independentes". WEBER, 2004, p. 61.
} 
potência real no território. A nobreza tradicional terá que se conformar ao novo sistema apoiado por parcela substancial da população, cansada dos conflitos entre senhores feudais.

Shakespeare parece, deliberadamente, estabelecer um paralelo entre a postura de Gonzalo e a dos utopistas, que, sem experiência concreta no cotidiano do poder, criam mundos abstratos. Guiado pelos conselhos de Gonzalo, Próspero tornou-se o soberano... de uma ilha deserta, habitada apenas por espíritos e por um selvagem. O que vemos em cena, ao longo da peça, é, precisamente, o contra-argumento de Shakespeare à utopia de Gonzalo - mas, ao mesmo tempo, a rejeição à prática de realpolitik encampada por Antônio e Sebastian. Diversamente do rei idealizado por Gonzalo, Próspero irá aprender a punir - dosando a pena, no entanto, com a misericórdia.

\section{Conclusão}

Se as utopias do século XVI não constituem libelos abolicionistas, tampouco são esboços da sociedade disciplinar. É necessário reconhecer a verdadeira dimensão que o Direito e o poder judicante ocupam em tais textos, sem projetar, neles, categorias forjadas nos dois últimos séculos com base em filosofias anti-humanistas. Jakob Burckhardt, pioneiro nos estudos sobre a Renascença, intitulou um dos capítulos do célebre A cultura do Renascimento na Itália como "O Estado como obra de arte" (BURCKHARDT, 1991). No entender do grande historiador da Basiléia, foi no Renascimento que, em definitivo, o Ocidente compreendeu a dimensão artificial/artificiosa do espaço público. As instituições políticas, no Renascimento, deixarão de ser vistas como um micro-cosmos que reflete uma ordem pré-dada, inscrita no universo. Não é a Natureza, Deus ou a Razão abstrata que fundam a cidade - é ela fruto de experimentalismos, de contingências históricas, da cultura. A conscientização de que a organização política não constitui uma (como queriam os escolásticos) "segunda natureza", mas é fruto de decisões pontuais, tentativas e erros, impacta, indubitavelmente, o imaginário do período. O contato com o novo mundo - com regimes políticos tão diversos daqueles conhecidos pela Cristandade acentua a percepção da relatividade (da precariedade) das estruturas sociais. A estrutura da cidade não se apóia em forças transcendentes - e atemporais

-; é auto-fundante e auto-legitimadora. É essa percepção que permite a eclosão da literatura utópica. Se o ordenamento jurídico da cidade dos homens não espelha o ordenamento jurídico da cidade de Deus, então pode ser objeto de modificações. Os limites da engenharia social 
passam a ser os limites da imaginação. É dentro desses esforços que, em vista da revitalização e da energização da comunidade, diferentes posicionamentos serão assumidos pelos utopistas no que tange à aplicação de penas.

\section{Referências}

ALMEIDA, Philippe Oliveira de. O navio afundado e o submarino - a memória do legado jurídico-político greco-romano na Igreja medieval. V JORNADA BRASILEIRA DE FILOSOFIA DO DIREITO, novembro de 2011, Belo Horizonte. Anais da V Jornada Brasileira de Filosofia do Direito: resumos expandidos. Belo Horizonte: Associação Brasileira de Filosofia do Direito e Sociologia do Direito, 2012, p. 174 a 180.

ARAÚJO, Carolina. A possível República de Platão. Morus - Utopia e Renascimento, Campinas, n. 6, 2009, p. 221 a 228.

BACON, Francis. Nova Atlântida. Novum Organum; Nova Atlântida. Tradução de José Aluysio Reis de Andrade. São Paulo: Nova Cultural, 1999.

BALDACCHINI, Michele. Vita di Tommaso Campanella. Napoli: Aldo Manuzio, 1847. A obra pode ser encontrada, em sua integralidade, no endereço eletrônico <https://archive.org/stream/vitaditommasoca00baldgoog\#page/n9/mode/2up>, acessado em 16 de agosto de 2015.

BURCKHARDT, Jakob. A cultura do Renascimento na Itália: um ensaio. Tradução de Sérgio Tellaroli. São Paulo: Companhia da Letras, 1991.

CAMPANELlA, Tommaso. La città del sole. Roma: Newton \& Compton, 1995 [o facsímile encontra-se disponível em <http://www.letteraturaitaliana.net/pdf/Volume_6/t332.pdf>, acessado em 24 de junho de 2015].

CAMPANELlA, Tommaso. A cidade do sol. Tradução de Aristides Lobo. São Paulo: Atena, 1958.

DELUMEAU, Jean. A civilização do Renascimento. Tradução de Manuel Ruas. Lisboa: Editorial Estampa, 1984, vol. 2.

ECO, Umberto. História das terras e lugares lendários. Tradução de Eliana Aguiar: Rio de Janeiro: Editora Record, 2013.

FLOWER, B. O. The century of sir Thomas More. Boston: The Arena Publishing, 1896. A obra pode ser encontrada, em sua integralidade, no endereço eletrônico <https://archive.org/stream/cu31924028009722\#page/n5/mode/2up〉, acessado em 9 de agosto de 2015.

FOUCAULT, Michel. Vigiar e punir: nascimento da prisão. Tradução de Raquel Ramalhete. Petrópolis: Vozes, 1987. 
GARCIA, Romay Conde. Fim da linha ou luz no fim do túnel? A tensão ordem/desordem e o urbanismo contemporâneo. Agenda Social, Rio de Janeiro, v. 2, n. 1, janeiro - abril de 2008.

GOTTLIEB, Erika. Dystopian fiction east and west: universe of terror and trial. Québec: McGill-Queen's University Press, 2001.

GREENBLATT, Stephen. Como Shakespeare se tornou Shakespeare. Tradução de Donaldson M. Garschagen e Renata Guerra. São Paulo: Companhia das Letras, 2011.

GROPIUS, Walter. Bauhaus: novarquitetura. Tradução de J. Guinsburg e Ingrid Dormien. São Paulo: Perspectiva, 2004.

HELIODORA, Bárbara. Expressão Dramática do Homem Político em Shakespeare. São Paulo: Paz e Terra, 1978.

JENDRYSIK, Mark Stephen. The Snake in the Garden: Crime and Punishment in Utopian Thought. The Washington and Jefferson College Review, Washington, v. 56, inverno de 2010.

MARLOWE, Christopher. A história trágica do Doutor Fausto. Tradução de A. de Oliveira Cabral. São Paulo: Hedra, 2006.

MILLET, René. Rabelais. Paris: Librairie Hachette et cie, 1892.

MONTAIGNE, Michel de. Sobre os canibais. Os ensaios: uma seleção. Tradução de Rosa Freire d'Aguiar. São Paulo: Companhia das Letras: 2010.

MORE, Thomas. Utopia. London: Richard Chilmell, 1684 [o facsímile encontra-se disponível em <https://archive.org/stream/utopia1684more\#page/n3/mode/2up>, acessado em 24 de junho de 2015].

MORE, Thomas. Utopia. Tradução de Anah de Melo Franco. Brasília: Editora Universidade de Brasília; Instituto de Pesquisa de Relações Internacionais, 2004. (Col. Clássicos IPRI).

MORTARI, Vicenzo Piano. Potere regio e consuetudine redatta nella Francia del Cinquecento. Quaderni Fiorentini per la storia del pensiero giuridico moderno, Firenze, v. 1, n. 1, p. 131 a $175,1972$.

NIETZSCHE, Friedrich. Escritos sobre história. Tradução de Noéli Correia de Melo Sobrinho. Rio de Janeiro: Ed. PUC-Rio; São Paulo: Loyola, 2005.

PIERONI, Geraldo. Jean Delumeau: historiador do passado e do presente cristão. XXVI SIMPÓSIO NACIONAL DE HISTÓRIA, 2011, São Paulo.Anais do XXVI Simpósio Nacional de História:São Paulo,ANPUH, 2011, p.1 a 9. Disponível em <http://www.snh2011.anpuh.org/resources/anais/14/1312407338_ARQUIVO_SaoPauloANP

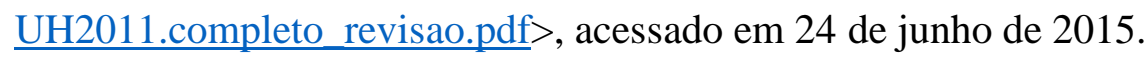

POCOCK, John Greville Agard. The Machiavellian Moment: Florentine Political Thought and the Atlantic Republican Tradition. Princeton: Princeton University Press, 1975. 
POPPER, Karl Raimund. A sociedade aberta e seus inimigos. Tradução de Milton Amado. Belo Horizonte: Ed. Itatiaia; São Paulo: Ed. da Universidade de São Paulo, 1974, vol. 1.

RABELAIS, François. Gargantua; Pantagruel. Paris: Larousse, 1932, 2 v.

RABELAIS, François. Gargântua e Pantagruel. Tradução de David Jardim Júnior. Belo Horizonte: Itatiaia, 2009.

RAMIRO AVILÉS, Miguel Angel. The Law-Based Utopia. Em GOODWIN, Barbara (Org.). The Philosophy of Utopia. London: Frank Cass, 2001.

RUGGIERO, Vicenzo. Crime and Punishment in Classical and Libertarian Utopias. Em MALLOCH, Margaret; MUNRO, Bill (Org.). Crime, Critique and Utopia. London: Palgrave Macmillan, 2013.

SCOTT, Nora (Org.). Pequenas fábulas medievais: fabliaux dos séculos XIII e XIV. Tradução de rosemary Costhek Abílio. São Paulo: Martins Fontes, 1995.

SHAKESPEARE, William. The Tempest. London: Macmillan and co., 1864 [o facsimile encontra-se disponível em <https://archive.org/stream/tempest03shakgoog\#page/n6/mode/2up >, acessado em 24 de junho de 2015].

SHAKESPEARE, William. A tempestade. Comédias e romances: teatro completo, volume 2. Tradução de Bárbara Heliodora. Rio de Janeiro: Nova Aguilar, 2009.

TASSO, Maria Laura. Il deviante nella città perfecta. Modelli repressivi nelle utopie di Campanella e More. Materiali per una storia della cultura giuridica, Bologna, fascículo 2, dezembro de 1999, p. 299 a 330.

UNGER, Roberto Mangabeira. What should legal analysis become? London, New York: Verso, 1996.

VENTURI, Robert et al. Aprendendo com Las Vegas: o simbolismo (esquecido) da forma arquitetônica. Tradução de Pedro Maia Soares. São Paulo: Cosac \& Naify, 2003.

VEYNE, Paul. Como se escreve a história; Foucault revoluciona a história. Tradução de Alda Baltar e Maria Auxiliadora Kneipp. Brasília: UnB, 1982.

VESPÚCIO, Américo. Novo mundo: as cartas que batizaram a América. Tradução de João Angelo Oliva, Janaína Amado Figueiredo e Luís Carlos Figueiredo. São Paulo: Editora Planeta do Brasil, 2003.

WEBER, Max. Ciência e política: duas vocações. Tradução de Leonidas Hegenberg e Octany Silveira Mota. São Paulo: Cultrix, 2004. 